\title{
Aplicação de sequência de ensino sobre eletrodinâmica: compreendendo o funcionamento de circuitos
}

\author{
Fernando Cezar Rivarola Ramirez¹, Thiago Chagas de Carvalho², José Carlos da Silva Oliveira ${ }^{3}$, Alcicléia \\ Souza Valente 4 \\ 1 Secretaria de Estado de Educação do Acre (SEE/AC) \\ $2,3,4$ Universidade Federal do Acre (UFAC)
}

Palavras-Chave: Ensino de Física, Eletrodinâmica, Circuitos Elétricos.

\section{Introdução}

Este trabalho surgiu diante da necessidade de modificar as abordagens iniciais realizadas no conteúdo sobre eletrodinâmica em uma turma de terceira série do ensino médio de uma escola pública de tempo integral na Cidade de Rio Branco, Acre. O primeiro conteúdo apresentado na unidade foi sobre potência elétrica e consumo de energia e repercutiu como uma grande dificuldade para as turmas que alegaram, através de um diagnóstico feito pela coordenação pedagógica da escola, dificuldades em compreender o novo conteúdo que estavam estudando. Diante dessa situação fez-se necessário modificar as abordagens que seriam feitas no próximo conteúdo que trata sobre circuitos elétricos. Os alunos apresentaram dificuldade em compreender os novos conceitos e associá-los à realidade. O próximo passo seria resolver exercícios que teriam como prérequisito parte dos conceitos estudados no começo da unidade e a turma mostrou-se apreensiva pelo nível de dificuldade. Para modificar essa expectativa foi realizada a aplicação de uma sequência de ensino inspirada nas teorias das hierarquias de aprendizagem de Gagné (MOREIRA, 1999) e a teoria de ensino em espiral de Bruner (MOREIRA, 1999), aplicando a leitura do livro didático em uso na escola, mostrando circuitos elétricos em pranchetas, medindo as grandezas elétricas e finalizando com apresentação de simulador de circuitos elétricos da plataforma Phet Interative Simulations ${ }^{1}$. O processo de avaliação das aulas incluiu a construção de um mapa conceitual para verificação da aprendizagem desenvolvida (MOREIRA, 2006).

\section{Metodologia e Material}

A sequência de ensino apresentada para coordenação de uma escola pública da zona urbana da cidade de Rio Branco-AC, previu seis encontros com uma turma de terceira série do ensino médio que possui 36 alunos frequentando as aulas. O primeiro momento de aula foi com a revisão das grandezas elétricas apresentadas no conteúdo anterior sobre consumo de energia. No segundo momento abordamos o livro didático em uso com a leitura e comparações com evidências do cotidiano do aluno, verificando através de questionamentos diretos à turma onde eles já tiveram contato com as nomenclaturas apresentadas. No terceiro momento utilizamos a prancheta de circuitos (figura 1) e o multímetro para verificar na prática onde se manifestam as grandezas elétricas, retirando dados na prática e aplicando nas fórmulas da Lei de Ohm apresentadas na leitura.

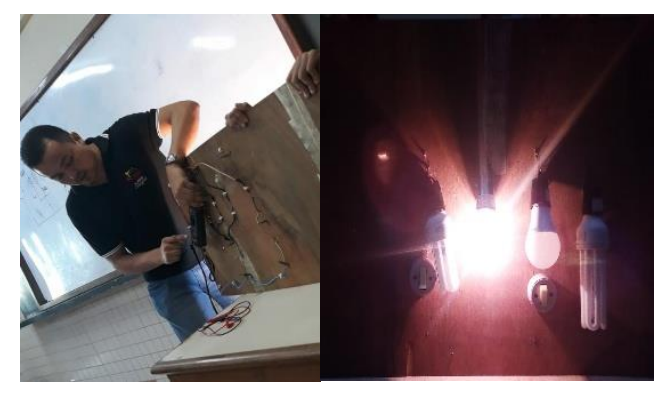

Figura 1 - Prancheta de circuitos. Fonte: Próprio autor

${ }^{1}$ Accessível no sitio: https://phet.colorado.edu/pt_BR/simulations/category/new 
No quarto momento foi apresentado, com a prancheta de circuitos, a disposição de ligações em série e paralelo. Essa prancheta possui um conjunto de lâmpadas e interruptores interligados e conectados por molas que permitem que sua configuração de ligação seja modificada para tipos de circuitos diferentes e a fiação exposta para verificar a maneira como os fios montam o circuito, podendo ter diversos pontos de medição de tensão e corrente elétrica. Para o quinto momento nos utilizamos de uma aula com projetor de imagens para apresentar o simulador de circuitos Phet Simulations na aplicação de circuitos de corrente contínua e as disposições de circuitos em série e paralelo com as respectivas grandezas elétricas presentes. Vale ressaltar que, no momento anterior e neste, nos apoiamos no uso de uma demonstração investigativa em virtude da disposição de materiais em número insuficiente para todos os alunos, bem como a dinâmica das aulas previstas (SASSERON; MACHADO, 2012). No sexto e último momento foi proposto a elaboração de um mapa conceitual para verificar a aquisição e apropriação da aprendizagem desta sequência de ensino.

\section{Resultados preliminares}

Com o desenvolvimento das atividades propostas foram superadas as ansiedades quanto a compreensão de um novo conteúdo. Pois os alunos dessa escola que chegaram ao terceiro ano do ensino médio tiveram mudança de professor e o tipo de conteúdo sugerido no plano de curso os obriga a manter um alinhamento de conceitos por muito tempo, impedindo que o aluno estude apenas para uma prova, mas sim, que saiba utilizar os conceitos de um conteúdo em novos momentos do ano letivo. Assim, a proposta de uma abordagem repetitiva e utilizando diferentes materiais que expõem os mesmos conceitos ajudaram no processo de aprendizagem em uma avaliação feita sobre os mapas conceituais elaborados, mostrando que os alunos conseguiram organizar as ideias durante a elaboração do mapa conceitual e percebendo a utilidade e eficiência destes mapas, destacando o funcionamento de circuitos elétricos e as grandezas envolvidas, obedecendo o processo de hierarquias de aprendizagens de Gagné bem como o processo de ensino em espiral de Bruner.

Destaca-se ainda que este processo seguirá com outras sequências de atividades e conteúdos e ainda prevê uma avaliação com prova objetiva, para verificar se além de compreensão do funcionamento dos circuitos elétricos de maneira qualitativa, também terão resultados de ordem quantitativa, com a utilização das fórmulas matemáticas envolvidas.

\section{Referências}

MOREIRA, M. A. A Teoria da Aprendizagem Significativa e sua Implementação em Sala de Aula. Brasília: Editora da UNB, 2006.

MOREIRA, M. A. Teoria de Aprendizagem. São Paulo: EPU, 1999.

SASSERON, L. H.; MACHADO, V. F.. Alfabetização Científica na Prática: Inovando a forma de ensinar Física. 1aㅡ ed. São Paulo: FTD, 2012.

GONÇALVES FILHO, A.; TOSCANO, C. Física: Interação e tecnologia, Volume 3. 2. ed. São Paulo: LEYA, 2016. 